\title{
Gambaran Pengetahuan Inter Professional Collaboration Pada Profesional Pemberi Asuhan Di Rumah Sakit Khusus Propinsi Jambi: Kajian
}

\author{
Ellis Mawarni ${ }^{1}$, Dachriyanus ${ }^{2}$, Estika Ariany Maisa ${ }^{3}$, Jufri Al Fajri ${ }^{4}$ \\ ${ }^{1}$ Mahasiswa Magister Keperawatan, Fakultas Keperawatan, Universitas Andalas, Padang, Sumatera Barat \\ ${ }^{2}$ Dosen Magister Keperawatan, Fakultas Keperawatan, Universitas Andalas, Padang, Sumatera Barat \\ ${ }^{3}$ Dosen Magister Keperawatan, Fakultas Keperawatan, Universitas Andalas, Padang, Sumatera Barat \\ ${ }^{4}$ Dosen Keperawatan, Sekolah Tinggi Ilmu Kesehatan Baiturrahim, Jambi \\ Email : ellis.sutriawan@yahoo.com, dachriyanus@phar.unand.ac.id, maisathika@gmail.com, star campuz@yahoo.com.
}

\begin{abstract}
Interprofessional collaboration (IPC) between nurses and doctors is associated with good outcomes for patients, especially in hospitalizations. Different professional cultures can be a barrier to nurses and doctors in an IPC effective and efficient. Effective IPC is important to ensure patient safety. To analyze how the image of Professional Care Givers is different in implementing IPC at Jambi Special Hospital. The research was cross-sectional, the population were nurses, doctors, pharmacists and nutritionists in Jambi Province Special Hospital 105 samples. Sampling with total sampling. AlTCS research instruments that have been modified as needed. Most of the application of IPC to Professional Care Givers in Jambi Province Special Hospital both on the partnership dimension, coordination, shared decision-making is only on the clearest reciprocal differences in the dimension of cooperation which is more than half less good. Conclusion: It is expected that the special hospital of Jambi Province will organize more integrated patient center care, which will have consequences for the implementation of the IPC, especially in terms of perceived cooperation.
\end{abstract}

Keywords: Inter Professional collaboration, Professional Caregiver, Special Hospital

\section{PENDAHULUAN}

Berbagai perspektif profesional manajemen risiko dan keselamatan pasien di Rumah Sakit semakin kompleks (Despins, 2015; Hinde et al., 2016; Mccomb et al., 2015) menurut World Health Organization (WHO), (2015) Rumah Sakit merupakan pemberi pelayanan kesehatan secara komprehensif, kuratif dan preventif serta sebagai pusat pelatihan dan penelitian bagi tenaga kesehatan. Sedangkan menurut UUD Nomor 44 (2009) Rumah Sakit adalah institusi pemberi pelayanan kesehatan yang menyediakan pelayanan rawat inap, rawat jalan, dan gawat darurat. Layanan Rumah Sakit sebagai sarana kesehatan dalam peningkatan kesehatan masyarakat.

Layanan rumah sakit terbagi menjadi dua yaitu Rumah Sakit Umum (menangani multiple penyakit) dan Rumah Sakit Khusus (menangani single penyakit seperti RS jiwa, RS mata, RS Jantung, RS Paru, dll) sebagai tujuan sarana kesehatan salah satunya menurut UUD Nomor 44, (2009) yaitu meningkatkan mutu dan mempertahankan standar pelayanan rumah sakit (Goldman et al., 2016; Kitto et al., 2015; Myron et al., 2017; T. Handayani, 2017), dan memberikan perlindungan terhadap keselamatan pasien. Didunia selama 20 tahun terakhir masalah untuk mengurangi bahaya dan meningkatkan keselamatan pasien menjadi sorotan penting (Reeves et al., 2017). Maka dari itu WHO, (2010) mencanangkan patient safety dengan strategi Inter professional calaboration (IPC) untuk menekan insiden yang merugikan pasien.

Inter professional calaboration (IPC) adalah kerjasama antara profesi kesehatan dengan latar pendidikan berbeda menjadi satu tim berkolaborasi untuk meningkatkan kualitas pelayanan kesehatan yang efektif (WHO, 2010). IPC menurut Institute of Medicine (IOM) bekerjasama efektif dalam tim memegang peranan utama dalam perbaikan sistem organisasi pemberian pelayanan berfokus pada pasien (Patient Cantared Care), karna lebih aman, efektif dan efisien
(Anthoine et al., 2014; Gree et al., 2015; Rousseau et al., 2017; Stephens et al., 2016). IPC merupakan strategi dalam meningkatkan kualitas pelayanan.

Strategi IPC bertujuan untuk patient safety, kekurangan SDM, dan mengubah sistem perawatan kesehatan yang lebih efektif (National Research Council 2000). IPC yang tidak baik akan memberikan dampak yang tidak baik bagi pihak Rumah Sakit, staf dan pasien sebagai penerima pelayanan. Adapun dampak yang ditimbukan adalah semakin meningkatnya ketidak puasan hingga maraknya tuntutan pasien atau keluarga pasien (Tang et al., 2018). Dengan demikian IPC merupakan hal yang penting dalam pelayanan rumah sakit.

Di Indonesia berdasarkan KKPRS dari tahun 2010 - tahun 2011 sebanyak 137 insiden. Dari 137 insiden tersebut Kejadian Nyaris Cidera (KNC) sebesar 40,15\%, sedangkan KTD sebesar $55,47 \%$ dan $4,38 \%$ lainnya (Syam, 2017). Sedangkan insiden yang mengakibatkan kematian $8,76 \%$. Data KTD belum mewakili kejadian sebenarnya di Indonesia. Data KTD masih langka untuk ditemukan, tetapi masalah malpraktik mulai banyak terungkap di media informasi. Hal ini terjadi karena pelayanan bermutu dan aman bagi pasien di Indonesia masih belum komprehensif. Kolaborasi yang baik akan menghasilkan outcom yang baik terutama pada PCC.

Outcome yang dihasilkan pada IPC terhadap PCC akan baik jika PPA (perawat, dokter, apoteker dan ahli gizi) melaksanakan proses IPC secara efektif (Bosch \& Mansell, 2015; Bursiek, April A, 2017; Goldman, Joanne, 2016). Dimana menurut Orchard et al., (2018), bahwa praktek IPC dibagi 4 dimensi dalam Assessment of Interprofessional Team Collaboration Scale (AITCS) meliputi partnerships, Cooperation, Coordination, Shared Decision Making.

Partnerships merupakan jenis hubungan kerja yang dilandasi hukum antara dua atau lebih orang, Cooperation adalah usaha yang dilakukan bersama antara individu atau kelompok manusia untuk mencapai 
tujuan persama dalam organisasi, Coordination merupakan sinkronisasi upaya anggota kelompok dalam memberikan kesatuan pendapat dan tindakan dalam pencapaian tujuan organisasi, dan Shared Decision Making atau dalam pengambilan keputusan secara bersama merupakan sebuah proses dalam semua pihak yang bekerja sama dalam mengeksplorasi pendapat yang relevan. Dimensi IPC ini sangat perlu diperhatikan dan dijalankan oleh rumah sakit.

\section{METODE PENELITIAN}

Penelitian ini merupakan penelitian kuantitatif menggunakan desain deskriptif dengan cross-sectional.

Populasi adalah Perawat, Dokter, Apoteker dan Ahli Gizi di Rumah Sakit Khusus Propinsi Jambi dengan jumlah 105 sampel, perawat $(n=77)$, dokter $(n=18)$, apoteker $(n=4)$, ahli gizi $(n=6)$. Sampel yang digunakan untuk mengetahui IPC di nilai perdimensi yang saling menilai sehingga sampel menjadi $(n=315)$. Pengambilan sampel dengan cara total sampling.

Pada pemilihan responden dipilih berdasarkan kriteria inklusi yang telah ditetapkan (1) Professional Pemberi Asuhan : Perawat, Dokter, Apoteker, dan Ahli Gizi yang berpengalaman kolaborasi dalam melakukan asuhan pasien. (2) Bekerja selama minimal 1 tahun.(3) bersedia dijadikan responden. Penelitian dilakukan di Rumah Sakit Khusus di Propinsi Jambi yang terdapat tenaga Professional Pemberi Asuhan sesuai dengan kriteria peneliti.

\section{HASIL DAN PEMBAHASAN}

Hasil yang didapat dengan distribusi frekuensi penerapan IPC dimensi partnership, cooperation, coordination dan shared decision - making pada profesional pemberi asuhan (Perawat, Dokter, Apoteker dan Ahli Gizi) di Rumah Sakit Khusus Propinsi Jambi dapat dilihat pada tabel berikut ini :

\section{Tabel 1 Distribusi Frekuensi Pengetahuan IPC Dimensi Partnership, Cooperation, Coordination dan Shared Decision - Making pada Profesional Pemberi Asuhan (Perawat, Dokter, Apoteker dan Ahli Gizi) di Rumah} Sakit Khusus Propinsi Jambi ( $\mathrm{N}=315)$

\begin{tabular}{llccccccc}
\hline No & Dimensi & \multicolumn{2}{c}{ Baik } & \multicolumn{2}{c}{ Kurang Baik } & \multicolumn{2}{c}{ Total } \\
& & F & f & f & f & & f \\
\hline $\mathbf{1}$ & Partnership & 175 & 55.6 & 140 & 44.4 & 315 & 100 \\
$\mathbf{2}$ & Cooperation & 155 & 49.2 & 160 & 50.8 & 315 & 100 \\
$\mathbf{3}$ & Coordination & 167 & 53.0 & 148 & 47.0 & 315 & 100 \\
$\mathbf{4}$ & Shared Decision-Making & 163 & 51.7 & 152 & 48.3 & 315 & 100 \\
\hline
\end{tabular}

Berdasarkan tabel 1 dapat diketahui bahwa sebagian besar partnership responden di RSK adalah dalam kategori baik (55,6\%), sebagian besar cooperation responden di RSK dalam kategori kurang baik $(50,8 \%)$, sebagian besar coordination responden di RSJ dalam kategori baik $(53,0 \%)$ dan sebagian besar shared decision-making responden di RSJ dalam kategori baik (51,7\%). Jadi dapat disimpulkan bahwa penerapan IPC PPA di Rumah Sakit Khusus Jiwa Propinsi Jambi hanya dimensi cooperation yang lebih dari separuh kurang baik.

\section{Pembahasan}

Berdasarkan hasil penelitian yang sudah dilakukan peneliti tentang penerapan dimensi partnership, cooperation, coordination dan shared decision - making pada profesional pemberi asuhan (Perawat, Dokter, Apoteker dan Ahli Gizi) di Rumah Sakit Khusus Propinsi Jambi dapat diketahui bahwa sebagian besar partnership responden di RSK adalah dalam kategori baik (55,6\%), sebagian besar cooperation responden di RSK dalam kategori kurang baik $(50,8 \%)$, sebagian besar coordination responden di RSK dalam kategori baik (53,0\%) dan sebagian besar shared decision-making responden di RSK dalam kategori baik $(51,7 \%)$.

Hasil penelitan ini sejalan dengan penelitian Hardin (2018) yang diketahui bahwa sebagian besar pada nilai partnership yaitu pada dalam kategori baik $(60,6 \%)$. Hinde et al (2016) dalam penelitiannya juga didapati pada penelitian lebih dari separuh dimensi cooperation kurang baik (54,4\%). Lancaster (2015) menemukan hasil bahwa coordination dan shared dsecision-making petugas kesehatannya baik (59,5\% dan $64,8 \%$ ).

Inter Professional Collaboration (IPC) merupakan kondisi dimana berbagai profesi kesehatan bekerjasama dengan pasien, keluarga pasien, masyarakat, dan profesi kesehatan lain untuk memberikan pelayanan kesehatan dengan kualitas yang terbaik (Hinde et al, 2016). Menurut Hardin et al (2018) IPC dalam pelayanan perawatan kesehatan adalah ketika terjadinya interaksi dari tenaga kesehatan dengan latar belakang professional yang berbeda dengan tujuan memberikan layanan komprehensif dengan bekerjasama memberikan pelayanan efektif yang berpusat pada pasien. Hal ini dapat mendukung PPA dalam bermitra atau partnership agar terciptanya tim yang berkolaborasi yang efektif.

Menurut Orchard et al, (2018) elemen dari IPC dalam Assessment of Interprofessional Team Collaboration Scale (AITCS) terdiri dari 4 item yaitu partnerships, cooperation, coordination dan shared decision making. Partnerships atau kemitraan adalah sebagai beberapa pihak, baik pemerintah maupun swasta, yang semua orang di dalamnya menjadi mitra atau rekan kerja dalam meraih tujuan bersama dan memenuhi kewajiban serta menanggung resiko, tanggung jawab, sumber daya, kemampuan dan keuntungan secara bersama.

Cooperation atau kerjasama didefinisikan sebagai pekerjaan yang dilakukan oleh dua orang atau lebih, bekerja sama antar profesi agar dapat mencapai tujuan yang sebelumnya sudah direncanakan dan disepakati bersama. Di rumah sakit kerjasama tim sudah menjadi suatu kebutuhan untuk bisa mewujudkan keberhasilan dalam mencapai tujuan (Bosch \& Mansell, 2015). 
Coordination atau koordinasi adalah suatu kegiatan yang dilakukan oleh berbagai pihak yang sederajat untuk bersama mengatur atau menyepakati sesuatu dan saling memberikan informasi, sehingga proses pelaksanaan tugas dan keberhasilan pihak yang satu tidak mengganggu pihak yang lainnya (Kitto et al, 2015).

Shared decision-making atau pengambilan keputusan bersama adalah proses pengambilan keputusan tentang tindakan asuhan pasien berdasarkan kesepakatan bersama (Orchard et al, 2018). Menurut Espin et al, (2015) karakteristik pengambilan keputusan bersama meliputi: (a) dua atau lebih peserta terlibat; (b) semua pihak bekerja sama untuk mencapai kesepakatan tentang perawatan yang tersedia; (c) informasi dibagi antara semua individu yang terlibat; dan (d) kesepakatan kolaboratif tercapai untuk perawatan yang akan dilakukan dan diimplementasikan oleh Profssional Pemberi Asuhan (PPA).

PPA di rumah sakit memiliki peranan yang sangat penting. Menurut Liu et al, (2016), dalam waktu paling lama 24 jam setelah pasien diterima di rawat inap, perencanaan asuhan dikembangakan. Perkembangan pasien dapat dipantau oleh PPA yang sering berhubungan dengan pasien yaitu perawat yang selama 24 jam berada disamping pasien, kemudian Dokter, Apoteker dan Ahli Gizi. Berdasarkan assesmen ulang pasien oleh PPA, maka rencana dapat diperbaharui sesuai dengan perubahan kondisi pasien. Oleh sebab itu IPC antar PPA harus diperhatikan agar berjalan secara maksimal.

Pada penelitian yang telah dilaksanakan oleh peneliti terlihat bahwa dimensi IPC PPA RSK Provinsi Jambi sebagian besar baik, kecuali dimensi cooperation di RSK, yakni sebagian besar kurang baik $(50,8 \%)$. Berdasarkan analisis kuesioner yang dilakukan oleh peneliti, dapat diketahui bahwa sumber utama dari kurang baiknya cooperation di RSK terlihat dari distribusi jawaban kuesioner nomor 8 tentang cooperation, menurut $17,9 \%$ dan $36,8 \%$ responden menilai bahwa Perawat dan Dokter di RSK jarang mendengarkan dan mempertimbangkan pendapat anggota lain terkait proses rencana perawatan individu.

Dampak dari kolaborasi pada tim dapat mempengaruhi angka mortalitas, tingginya komplikasi, panjang lama hari rawat, tinggi biaya pengobatan, kepuasan pasien (Liu et al, 2016; Vestergaard \& Nørgaard 2017), Menurut Liu, Gerdtz, \& Manias (2016), Vestergaard \& Nørgaard (2017), dampak negatif tersebut ada yang mengakibatkan medical error , nursing error atau kejadian tidak diharapkan (KTD). Oleh karena itu diharapkan PPA dapat menjadi tim yang solid.

Oleh karena itu, untuk menciptakan kerjasama yang baik pada PPA di RSK, memaksimalkan asuhan yang diberikan pada pasien dan untuk menghindari munculnya perasaan tidak dihargai pada tim lainnya serta untuk efektifnya waktu dan ikatan kerja, maka peneliti berharap pada pihak PPA RSK khususnya Perawat dan Dokter untuk saling mendengarkan dan mempertimbangkan pendapat dari anggota tim lainnya. Selain itu peneliti berharap pihak RSK agar dapat melakukan kegiatan-kegiatan yang dapat meningkatkan hubungan baik dan kerjasama antar profesi seperti dengan mengadakan kegiatan formal dan informal secara terjadwal dan pelatihan integrasi kerja antar profesi sehingga IPC PPA dapat berjalan sebagaimana mestinya.

\section{DAFTAR PUSTAKA}

Alexanian, Janet $A$, et al. (2015). Beyond the Team: Understanding Interprofessional Work in Two North American ICUs*. CCM Journal, 43(September 2015), 9. https://doi.org/10.1097/CCM.0000000000001136

Ali, A., Meyer, C., \& Hickson, L. (2018). Patient-centred hearing care in Malaysia: what do audiologists prefer and to what extent is it implemented in practice? Speech, Language and Hearing, 21(3), 172-182.

https://doi.org/10.1080/2050571X.2017.1385167

Anggarawati, T., \& Sari, N. W. (2016). Kepentingan Bersama Perawat-Dokter Dengan Kualitas Pelayanan Keperawatan. Jurnal IImiah Kesehatan Keperawata, 12(1), 44-54.

Anthoine, E., Delmas, C., Coutherut, J., \& Moret, L. (2014). Development and psychometric testing of a scale assessing the sharing of medical information and interprofessional communication: The CSI scale. BMC Health Services Research, 14, 126. https://doi.org/10.1186/1472-6963-14-126

Bosch, B., \& Mansell, H. (2015). Interprofessional collaboration in health care: Lessons to be learned from competitive sports. CPJ/RPC, 148(4), https://doi.org/10.1177/1715163515588106

Bursiek, April A, et al. (2017). Use of High-Fidelity Simulation to Enhance Interdisciplinary Collaboration and Reduce Patient Falls. $J$ Patient Safety, 00(00), 1-6.

Calpe, L. B., Fernández, B. M., \& Martínez, E. R. (2016). Análisis de la intensidad de colaboración profesional entre enfermeras en un área de críticos. Enfermería Intensiva, (xx), 1-7. https://doi.org/10.1016/j.enfi.2015.12.001

Connor, P. O., Dea, A. O., Lydon, S., Offiah, G., Scott, J., Flannery, A., ... Byrne, D. (2016). A mixedmethods study of the causes and impact of poor teamwork between junior doctors and nurses. International Journal for Quality in Health Care, 17. https://doi.org/10.1093/intqhc/mzw036

Despins, L. A. (2015). Patient safety and collaboration of the intensive care unit team. Critical Care Nurse, 29(2), 85-91. https://doi.org/10.4037/ccn2009281

Dewi, W. N., Evans, D., Bradley, H., \& Ullrich, S. (2013). Person-centred care in the indonesian health-care system. International Journal of Nursing Practice, 20(6), 616-622. https://doi.org/10.1111/ijn.12213

Donovan, A. L., Aldrich, J. M., Gross, A. K., Barchas, D. M., Thornton, K. C., Schell-chaple, H. M., ... Lipshutz, A. K. M. (2018). Interprofessional Care and Teamwork in the ICU. Ccmjournal, 1-11. https://doi.org/10.1097/CCM.0000000000003067

Elrifda, S. (2011). Budaya Patient Safety dan Karakteristik Kesalahan Pelayanan: Implikasi Kebijakan di Salah Satu Rumah Sakit di Kota Jambi Patient Safety Culture and Healthcare Error 
Characteristics : Implication of Policy at A Hospital in, 6(05), 67-76.

Godden-webster, A., \& Murphy, G. (2014). Interprofessional Collaboration in Practice: A Guide for Strengthening Student Learning Experiences. Dalhousie University.

Goldman, Joanne, at el. (2016). A sociological exploration of the tensions related to interprofessional collaboration in acute-care discharge planning, 1820(April). https://doi.org/10.3109/13561820.2015.1072803

Green, B. N., \& Johnson, claire D. (2015). Interprofessional collaboration in research, education, and clinical practice: working together for a better future. J Chiropr Education, 29(1), 110. https://doi.org/10.7899/JCE-14-36

Hamlan, N. M. (2015). The Relationship Between InterProfessional Collaboration, Job Satisfaction, and Patient Safety Climate for Nurses in a TertiaryLevel Acute Care Hospital, (September 2015).

Hardin, L., Kilian, A., \& Spykerman, K. (2018). Competing health care systems and complex patients: An inter-professional collaboration to improve outcomes and reduce health care costs. Journal of Interprofessional Education \& Practice, 7(2017), 5-10.

https://doi.org/10.1016/j.xjep.2017.01.002

https://doi.org/10.1177/0046958018754739

Hinde, T., Gale, T., Anderson, I., Roberts, M., Sice, P., Hinde, T., ... Sice, P. (2016). A study to assess the influence of interprofessional point of care simulation training on safety culture in the operating theatre environment of a university teaching hospital. Journal of Interprofessional Care, $\quad 30(10$ April 2015), 251-253. https://doi.org/10.3109/13561820.2015.1084277

Holmes, D. (2018). Teori Komunikasi Media Teknologi Dan Masyarakat (II). Yogayakarta: Pustaka Pelajar Kh.

$\mathrm{JCl}$, \& WHO. (2007). Communication During Patient Hand-Overs, 1(May).

Kitto, S., Marshall, S. D., Mcmillan, S. E., Shearer, B., Buist, M., Grant, R., ... Wilson, S. (2015). Rapid response systems and collective (in ) competence: An exploratory analysis of intraprofessional and interprofessional activation factors, 1820(4), 340-346. https://doi.org/10.3109/13561820.2014.984021

Komisi Akriditasi Rumah sakit. (2017). Standar Nasional Akriditasi Rumah sakit (SNARS)_edisi1 (1st ed.). jakarta.

Marquis, B. L., \& Huston, C. J. (2003). Leardership Roles and Management Functions In Nursing: Theory and Application (4th ed.). USA: Lippincott Williams \& Wilkins.

Martin, J. S., Ummenhofer, W., Manser, T., \& Spirig, R. (2010). Interprofessional collaboration among nurses and physicians: making a difference in patient outcome. Of Medical Sciences, (1 September 2010), 1-7. https://doi.org/10.4414/smw.2010.13062

Ndraha, T. (2011). Kybernology (Ilmu Pemerintahan Baru) 2 (2nd ed.). jakarta: Rineka Cipta.
Notoatmojodjo, S. (2012). Metodologi Penelitian Kesehatan. Jakarta: Rineka Cipta. Retrieved from http://www.digilib.unipdu.ac.id/beranda/index.php? p=show_detail\&id=3563

O'Sullivan, R. G. (2012). Collaborative Evaluation within a framework of stakeholder-oriented evaluation approaches. Evaluation and Program Planning, 35(4),

518-522. https://doi.org/10.1016/j.evalprogplan.2011.12.005

Orchard, C. A., King, G. A., Khalili, H., \& Bezzina, M. B. (2012). Assessment of Interprofessional Team Collaboration Scale (AITCS): Development and Testing of the Instrument. $J$ CONTINUING EDUCATION IN THE HEALTH PROFESSIONS, 1(32), 58-67. https://doi.org/DOI: 10.1002/chp

Orchard, C., Pederson, L. L., Read, E., Mahler, C., \& Laschinger, H. (2018). Assessment of Interprofessional Team Collaboration Scale (AITCS). Journal of Continuing Education in the Health Professions, 38(1), 11-18. https://doi.org/10.1097/CEH.0000000000000193

Permenkes. Peraturan Mentri Kesehatan Republik Indonesia Nomor 26 Tahun 2013 Tentang Penyelenggaraan Pekerjaan dan Praktik Tenaga Gizi (2013). Jakarta.

Permenkes. Peraturan Mentri Kesehatan Republik Indonesia Nomer 35 Tahun 2014 Tentang Standar Pelayanan Kefarmasian di Apotek (2014). Jakarta.

PPNI. (2005). Standar Kompetensi Persatuan Perawat Nasional Indonesia ( PPNI ). Jakarta. Retrieved from

ebookduniakesehatan.files.wordpress.com/2014/1 $1 / .$.

Reeves, S., Clark, E., Lawton, S., Ream, M., \& Ross, F. (2017). Examining the nature of interprofessional interventions designed to promote patient safety: a narrative review, 29(February), 144-150. https://doi.org/10.1093/intqhc/mzx008

Regan, S., \& Regan, S. (2015). The influence of empowerment, authentic leadership , and professional practice environments on nurses perceived interprofessional collaboration, 1-8. https://doi.org/10.1111/jonm.12288

Robbin, S. p., Judge, T. A., \& Millet, B. (2015). Organizational Behavior: The Essentials (16th ed.). english: Pearson Education. Retrieved from books.google.com

Rokhmah, N. A., \& Anggorowati. (2017). Komunikasi efektif dalam praktek kolaborasi interprofesi sebagai upaya meningkatkan kualitas pelayanan. Journal of Health Studies, 1(maret 2017), 65-71.

Romijn, A., Teunissen, P. W., Bruijne, M. C. De, Wagner, C., \& Groot, C. J. M. De. (2017). Interprofessional collaboration among care professionals in obstetrical care : are perceptions aligned? BMJ Quality \& Safety, O(26 September 2017), 1-8. https://doi.org/10.1136/bmjqs-2016006401

Rousseau, C., Pontbriand, A., \& Nadeau, L. (2017). Perception of Interprofessional Collaboration and Co-Location. J Can Acad Child Adolesc Psychiatry, (27 juni 2017).

Sani K, F. (2016). Metodologi Penelitian Farmasi 
Komunitas dan Eksperimental (I). Yogyakarta: Budi Uama.

Scotten, M., Laverne, E., Malicoat, A., \& Paolo, A. M. (2015). Minding the gap: Interprofessional communication during inpatient and post discharge chasm care §. Patient Education and Counseling, 98(17 maret 2015), 895-900. https://doi.org/10.1016/j.pec.2015.03.009

Siegler, E. L., \& Whitney, F. W. (2000). Kolaborasi Perawat-Dokter. (M. Ester, Ed.) (1st ed.). Jakarta: Buku Kedokteran EGC.

Siga, P. kKnisius, Novieastari, E., \& Suhendri, A. (2018). Optimalisasi Pelaksanaan Discharge Planning. Chmk Nursing Scientific Journal, 2(April).

Soekanto, S. (2012). Sosiologi Suatu Pengantar (1st ed.). Jakarta: Rajawali perss.

Stephens, T., Hunningher, A., Mills, H., \& Freeth, D. (2016). An interprofessional training course in crises and human factors for perioperative teams teams. Journal of Interprofessional Care, 1820(17 June).

https://doi.org/10.1080/13561820.2016.1185096

Sugiyono. (2018). Metode Penelitian Kuantitatif. (Setiyawami, Ed.) (1st ed.). Bandung: Alfabeta. Retrieved from www.cvalfabeta.com

Sullivan, T. (2018). Institute of Medicine Report - The Future of Nursing: Leading Change, Advancing Health. Nepal. Retrieved from https://www.policymed.com/2011/02/institute-ofmedicine-report-the-future-of-nursing-leadingchange-advancing-health.html

Syam, N. S. (2017). Implementasi Budaya Keselamatan Pasien Oleh Perawat di Rumah Sakit Ibnu Sina Makassar. Fakultas Kesehatan Masyarakat, 11(2), 174-180.

T. Handayani, V. et. a. (2017). Segmentasi Geografi dan Perilaku Berpengaruh terhadap Keputusan Memilih Layanan Rawat Inap di Rumah Sakit. Jurnal Kedokteran Brawijaya, 29(februari 2017), 255-260.

https://doi.org/10.21776/ub.jkb.2017.029.03.13

Tang, T., Lim, M. E., Mans, E., Mclachlan, A., \& Quan, S. D. (2018). International Journal of Medical Informatics Clinician user involvement in the real world: Designing an electronic tool to improve interprofessional communication and collaboration in a hospital setting, 110(July 2017), 90-97. https://doi.org/10.1016/j.ijmedinf.2017.11.011

Temkin-Greener, H., Gross, D., Kunitz, S. J., \& Mukamel, D. (2004). Measuring interdisciplinary team performance in a long-term care setting. Medical Care, 42(5), 472-481. https://doi.org/10.1097/01.mlr.0000124306.28397. e2

Undang-Undang. Undang-Undang Republik Indonesia Nomor 29 Tahun 2004 Tentang Praktik Kedokteran (2004). Jakarta. Retrieved from luk.staff.ugm.ac.id/atur/UU29-

2004PraktikKedokteran.pdf

Undang-Undang. Undang-Undang Republik Indonesia Nomer 38 Tahun 2014 Tentang Keperawatan (2014). jakarta. Retrieved from www.hukumonline.com
Undang-undang Nomor 44. Undang-Undang Republik Indonesia Nomer 44 Tahun 2009 Tentang Rumah Sakit (2009). Jakarta. Retrieved from www.hukumonline.com

Vestergaard, E., \& Nørgaard, B. (2017). Interprofessional collaboration: An exploration of possible prerequisites for successful implementation. Journal of Interprofessional Care, oO(00) $1-11$. https://doi.org/10.1080/13561820.2017.1363725

Vittadello, F., Mischo-kelling, M., Wieser, H., Cavada, L., Naletto, C., Fink, V., ... Cavada, L. (2017). A multiple-group measurement scale for interprofessional collaboration: Adaptation and validation into Italian and German languages. Journal of Interprofessional Care, 00(020 oktober 2017), $1-8$. https://doi.org/10.1080/13561820.2017.1396298

Wang, C., \& Chen, Y. (2017). Reimbursement and hospital competition in China. Economic Research-Ekonomska Istraživanja, 9664, 1-15. https://doi.org/10.1080/1331677X.2017.1340177

WHO. (2010). Human Resources for Health Framework for Action on Interprofessional Education \& Collaborative Practice.

Zhao, J., Gao, S., Wang, J., Liu, X., \& Hao, Y. (2016). Differentiation between two healthcare concepts: Person-centered and patient-centered care. International Journal of Nursing Sciences, 3(31 agustus), https://doi.org/10.1016/j.ijnss.2016.08.009 398-402. 